\title{
Central Nervous System Epidermoid Cyst
}

National Cancer Institute

\section{Source}

National Cancer Institute. Central Nervous System Epidermoid Cyst. NCI Thesaurus.

Code C5507.

A lesion which is characterized by an irregularly nodular opalescent wall which has caused it to be termed a "pearly tumor". The Intramural contents are soft and waxy with a variable amount of cholesterol. 